\title{
Control constitucional en el sistema arbitral ecuatoriano: ¿Garantismo o Intervencionismo?
}

\author{
Camilo Muriel Bedoya* \\ Recibido/Received: 26/01/2016 \\ Aceptado/Accepted: 19/08/2016
}

SUMARIO: 1. Introducción. 2. Corte Constitucional, arbitraje y la acción extraordinaria de protección. 3. Pronunciamientos de la Corte Constitucional. 3.1 Sentencia Caso No. 0008-2008-DI. 3.2 Sentencia No. 0006-10-SEP-CC. 3.3 Sentencia No. 063-12-SEP-CC. 3.4 Sentencia No. 155-12-SEP-CC. 3.5 Sentencia No. 169-12-SEP-CC. 3.6 Sentencia No. 081-13-SEP-CC. 3.7 Sentencia No. 123-13-SEPCC. 3.8 Sentencia No. 173-14-SEP-CC. 3.9 Sentencia No. 113-15SEP-CC. 3.10 Sentencia No. 124-15-SEP-CC. 3.11 Sentencia No. 270-15-SEP-CC. 4. Eclecticismo en la Corte. 5. Conclusión.

PALABRAS CLAVE: control constitucional, laudos arbitrales, acción extraordinaria de protección, Ecuador.

KEYWORDS: constitutional control, arbitral awards, extraordinary action of protection, Ecuador.

RESUMEN: La Corte Constitucional del Ecuador ha establecido que los laudos arbitrales pueden ser objeto de control constitucional. Existe un debate previo respecto a la aplicabilidad de recursos disponibles en procedimientos ordinarios

* Asociado en Pérez Bustamante \& Ponce Abogados. Abogado y Licenciado en Ciencias Jurídicas por la Pontificia Universidad Católica del Ecuador, y LL.M., por la University College London.

C. Muriel, "Control constitucional en el sistema arbitral ecuatoriano: ¿Garantismo o Intervencionismo?", Revista Ecuatoriana de Arbitraje, No. 7, 2015. 
en contra de laudos arbitrales y de las sentencias que resuelven su nulidad; sin embargo, la jurisprudencia ecuatoriana ha sido ecléctica y ahora, adicionalmente, la aplicación de la acción extraordinaria de protección en arbitraje se suma a este incierto panorama jurídico, levantando aún más dudas respecto a la pertinencia, residualidad y extraordinariedad de esta acción. De esta forma, las cortes enfrentan la delicada tarea de proceder respetando y aplicando la Constitución, pero también la especialidad y naturaleza de las instituciones que esta protege; concibiéndose así una dialéctica que incidirá directamente en la eficacia del sistema jurídico ecuatoriano y su administración de justicia.

ABSTRACT: The Constitutional Court of Ecuador has established that arbitral awards may be constitutionally reviewed or controlled by it. There is a previous debate regarding the applicability of the available recourses within ordinary proceeding against

arbitral awards and judgments that resolve their annulment; however, the Ecuadorian case law has been eclectic and now, additionally, the application of the extraordinary action of protection within arbitration is added to this uncertain juridical environment, raising even more doubts regarding the relevance, residuality and extraordinariness of this action. Accordingly, the courts face the delicate task of proceeding respecting and applying the Constitution, but also the speciality and nature of the institutions protected by it; thus, conceiving a dialectic that will directly influence the efficacy of the Ecuadorian legal system and its administration of justice.

\section{INTRODUCCIÓN}

Se define actualmente al Ecuador como un "Estado constitucional de derechos y justicia"1 y ya no como un "estado social de derecho" ${ }^{\prime 2}$. La Constitución de 2008 tomó un enfoque diferente al

1. Constitución de la República del Ecuador de 2008 (CRE), Art. 1, RO No. 449, 20/10/2008.

2. Constitución Política de la República del Ecuador de 1998, Art. 1, RO No. 1, 11/08/1998. 
de su predecesora y ahora los derechos constitucionalmente protegidos son el eje de todo el sistema jurídico, aunque esto no implique que Ecuador haya dejado de ser un Estado de Derecho ${ }^{3}$. Así, este nuevo sistema busca establecer un régimen proteccionista que garantice al máximo los derechos reconocidos por la Constitución y, para alcanzar este objetivo, las cortes ecuatorianas enfrentan grandes -aunque no nuevos- desafíos. Este trabajo analizará una de las áreas que quizás ha reflejado el mayor de los aparentes antagonismos y preocupantes incertidumbres, el control constitucional en el ámbito arbitral. Específicamente, se analizará la evolución del tratamiento de la acción extraordinaria de protección en el arbitraje, así como las principales sentencias que ha emitido la Corte Constitucional ecuatoriana relacionadas con el control constitucional de laudos arbitrales y de sentencias o decisiones que resuelven su nulidad.

Existe desde hace varios años una delicada tensión entre el sistema arbitral y el régimen constitucional ecuatoriano. El control constitucional de laudos y los pronunciamientos de la Corte Constitucional, sin embargo, no han pasado inadvertidos ${ }^{4}$ y es necesario continuar con un estudio crítico del tratamiento de la acción extraordinaria de protección dentro de un mecanismo de resolución de conflictos tan trascendental como lo es el arbitraje. En los siguientes apartados se evidenciará este dualismo entre la elección de largos procedimientos -pero en principio llenos de seguridades- y la aplicación de los principios rectores del arbitraje, tales como la celeridad y la finalidad ${ }^{5}$.

3. Véase H. Salgado Pesantes, "Democracia y participación política en un Estado Social de Derecho", en H. Salgado Pesantes et al, Nuevos Retos del Constitucionalismo Ecuatoriano: Democracia, Garantías y Derechos, AED-PUCE, 2011, p. 2.

4. Véase, E. NeIRA, La Constitución de 2008 y el arbitraje bajo la ley ecuatoriana: análisis de dos problemas que surgen antes que del texto constitucional, de su equivocada aplicación, $<$ http://goo.gl/6cTO7A> (15/12/2015); C. Muriel, Constitutional Review of Arbitral Awards: Between Protectionism and Interventionism, $<\mathrm{http} / /$ goo.gl/hbFg3o $>$ (15/12/2015); y, H. GARCíA, Procedure of Annulment of an Arbitral Award in Ecuador: An Arbitral Odyssey, <http://goo.gl/hN8Vbc $>$ (15/12/2015). Véase adicionalmente, F. GonZÁLEZ DE Cossío, "Procesos constitucionales y procesos arbitrales: ¿agua y aceite?”, Revista Ecuatoriana de Arbitraje, No. 6, 2014, pp. 229-248.

5. Véase, A. Dillon, The History of a Lawsuit in the Republic of Ecuador, Spottiswoode \& Co 1864, reimpreso por MOML, p. iv. En 1864, en un reporte a la Cámara de los Lores, se afirmó que en Ecuador "an ordinary suit baffles all calculation, and not unfrequently exceeds the natural term of a man's life." 
Más allá de la todavía vigente discusión legal respecto a la procedencia de recursos ordinarios y extraordinarios en contra de las sentencias que resuelven la nulidad de un laudo arbitral ${ }^{6}$, las preguntas que surgen y que se considerarán a lo largo de este trabajo residen en la compatibilidad del control constitucional y el sistema arbitral, la efectividad de este control y su contribución a la justicia. De las sentencias y casos analizados, no obstante, se hará evidente que el tratamiento ecléctico de la extraordinariedad y residualidad de la AEP y los diferentes criterios que han tomado los administradores de justicia han derivado en una mayor incertidumbre e inseguridad jurídica, contrario a lo que originalmente buscó, al menos en teoría, la Constitución de 2008.

\section{Corte Constitucional, ARbitraje Y LA ACCIÓN EXTRAORDINARIA DE PROTECCIÓN}

Para PAULSSON, su idea of arbitration supone la existencia de una resolución obligatoria que pone fin a una disputa, la cual es aceptada con serenidad por aquellos que soportan sus consecuencias debido a la especial confianza que tienen en quienes fueron escogidos para dicho fin $^{7}$. Es importante tomar en cuenta que si bien la autonomía de las partes se encuentra protegida por la mayoría de las legislaciones, esta no es absoluta ${ }^{8}$. De esta forma, es necesaria la intervención de las cortes para enmendar determinadas irregularidades y el alcance de este control es el que determinará si existe una asistencia beneficiosa o intervención disruptiva del sistema.

Varias normas dieron lugar al actual control constitucional del sistema arbitral. En primer lugar, la Constitución establece que la Corte Constitucional es el "máximo órgano de control, in-

6. Véase, F. Albuja, “La acción de nulidad de un laudo arbitral: ¿un proceso de conocimiento?”, Revista Ecuatoriana de Arbitraje, No. 6, 2014, pp. 271-284.

7. Cfr. J. PAulsson, The Idea of Arbitration, OUP, 2013, p. 1. El autor afirma además: “Acceptance of arbitration is a distinctive feature of free societies. It is rejected by totalitarian states. It is viewed with sceptism by enthusiasts of central planning."

8. A. Tweeddale y K. Tweeddale, Arbitration of Commercial Disputes: International and English Law and Practice, OUP, 2010, p. 249. 
terpretación constitucional y de administración de justicia en esta materia"9 y que sus sentencias y autos son definitivos e inapelables $^{10}$. Por otro lado, dentro de las garantías jurisdiccionales definidas por la Constitución, se regula a la acción extraordinaria de protección (AEP), la cual procede en contra de sentencias, autos definitivos y resoluciones con fuerza de sentencia en los que se haya violado derechos constitucionales, y en los que se demuestre que se han agotado todos los recursos ordinarios y extraordinarios, a menos que "sean ineficaces o inadecuados o que la falta de interposición de estos recursos no fuera atribuible a la negligencia del titular del derecho constitucional vulnerado ${ }^{11}$."

Adicionalmente, el arbitraje se encuentra constitucionalmente reconocido como un procedimiento alternativo para la solución de $\operatorname{conflictos}^{12}$ y la Ley de Arbitraje y Mediación (LAM) ${ }^{13}$ les atribuye a los laudos arbitrales el efecto de sentencia ejecutoriada y de cosa juzgada ${ }^{14}$. La LAM expresamente establece que los laudos arbitrales son inapelables -aunque sí pueden ser aclarados o ampliados- y que no son susceptibles de ningún otro recurso que no establezca esta ley ${ }^{15}$. En consecuencia, la única acción posible en contra de un laudo, prevista en la LAM, es la acción de nulidad, la cual deberá basarse en una de las causales específicas determinadas por esta misma ley ${ }^{16}$.

Todos estos elementos configuraron el uso -y potencial abuso- de la AEP como un mecanismo para impugnar laudos $\mathrm{y}$, similarmente, decisiones relacionadas con su nulidad. La acción extraordinaria de protección se consolidó como una variable más

9. CRE, N. 1, Arts. 429 y 436.

10. CRE, N. 1, Art. 440.

11. Véase, CRE, N. 1, Arts.94 y 437; y Ley Orgánica de Garantías Jurisdiccionales y Control Constitucional (LOGJCC), RO Sup. No. 52, 22/10/2009. Véase particularmente, Arts. 58, 61 y 63.

12. CRE, N. 1, Art. 190: "Se reconoce el arbitraje, la mediación y otros procedimientos alternativos para la solución de conflictos. Estos procedimientos se aplicarán con sujeción a la ley, en materias en las que por su naturaleza se pueda transigir. En la contratación pública procederá el arbitraje en derecho, previo pronunciamiento favorable de la Procuraduría General del Estado, conforme a las condiciones establecidas en la ley".

13. Ley de Arbitraje y Medicación (LAM), RO No. 417, 14/12/2006.

14. LAM, N. 13, Art. 32.

15. Ídem, Art. 30.

16. Ídem, Art. 31. 
a una práctica en donde no había consenso en las cortes. Antes de la vigencia de la Constitución de 2008 existía un debate previo respecto a la procedencia de recursos en contra de la sentencia que resuelve la acción de nulidad de un laudo arbitral. Como resultado, es posible encontrar posturas contrarias respecto a su procedencia tanto a nivel de Corte Provincial (y ex Cortes Superiores), así como de Corte Nacional (y de ex Corte Suprema).

De esta forma, se admitieron, inadmitieron, aceptaron y rechazaron recursos de apelación en contra de la sentencia que resuelve la nulidad de un laudo. De igual forma, se presentaron recursos de casación en contra de estas decisiones y a lo largo de estos procedimientos no es poco común encontrar, adicionalmente, solicitudes de aclaración y ampliación y recursos de hecho, tanto en contra de la negativa de un recurso de apelación, así como de uno de casación. La AEP hizo aún más complejos todos estos escenarios, dado que se alegaron violaciones constitucionales dentro de casos que reflejan todas estas posibles variaciones $^{17}$. En algunos casos todavía se ataca por medio de la AEP

17. Véase los casos en los que se deduce acción extraordinaria de protección presentados por: Esmeralda Lossa de Rosillo, Compañia ROS \& LO CÍA LTDA, Jorge Rosillo Claudet, Caso No. 1037-10-EP; Ecuador Bottling Corp (EBC), Caso No. 1443-10-EP; Fernando Marcelo Zaldúa y otros, Caso No. 1568-12-EP; Marcos Iván Caamaño Guerrero, en calidad de coordinador general jurídico y delegado de la ministra de Transporte y Obras Públicas y del procurador General del Estado, Caso No. 127911-EP y 1280-11-EP acumulados; Jorge Helmutt Salazar Vélez, Caso No. 1542-11-EP; Francisco Grijalva Muñoz, en calidad de Director Nacional de Asuntos Internacionales y Arbitraje de la Procuraduría General del Estado, y Marcelo Aguayo, en calidad de Director Nacional de Asesoría Jurídica y Procurador Judicial del ministro de Salud Pública, Caso No. 1703-11-EP; Clemente Bravo Riofrio e Ignacio Arias García, por los derechos que representan del Gobierno Autónomo Descentralizado de Santa Rosa, en calidades de Alcalde y Procurador Síndico Municipal, Caso No. 0976-12EP; CELTEL CONSTRUCCIONES Y SERVICIOS LTDA, Caso No. 1114-12-EP; Jaime Patricio Solines Coronel, en calidad de representante legal CONSTRUIR FUTURO S.A., Caso No. 1441-12-EP; Juan Xavier Ribas, en calidad de representante legal de la Compañia de Seguros Ecuatoriano Suiza S.A., Caso No. 0091-13-EP; Christel Gaibor Flor, en calidad de Directora Nacional de Asuntos Internacionales y Arbitraje de la Procuraduría General Subrogante del Estado, y Patricio Llerena, en calidad de Gerente General Subrogante de CNT, Caso No. 0501-13-EP; Rubén Dario León Vásquez, en calidad de Secretario Nacional de Telecomunicaciones SENATEL, Caso No. 0518-13-EP; Christel Gaibor Flor, en calidad de Directora Nacional de Asuntos Internacionales y Arbitraje encargada y delegada del Procurador General del Estado, Caso No. 0879-13-EP; Cristina González Camacho, en calidad de procuradora judicial de Othón Zevallos Moreno, gerente general y representante legal de Empresa Pública Metropolitana de Agua Potable y Saneamiento de Quito, Caso No. 0880-13-EP; Luis Alfredo Muñoz Neira, en calidad de liquidador designado por la Superintendencia de la empresa NATURA INC CIA, Caso No. 1000-13-EP; Pablo Sotomayor Fernández, representante legal del CONSORCIO U.S.V. Construcciones C.A., Caso No. 1053-13-EP; Carlos Julio Machado Vallejo, en calidad de gerente general subrogante y representante legal de la Empresa Pública Metropolitana de Desarrollo Urbano de Quito EPMDUQ, Caso No. 1338-13-EP; Miguel Ángel Valdivieso Valencia, Caso No. $1362-$ 
la no admisión o rechazo de recursos ordinarios o extraordinarios en contra de la sentencia que resuelve la nulidad de un laudo y son particularmente interesantes los casos en donde interviene una entidad pública o la Procuraduría General del Estado ${ }^{18}$. En la Tabla No. 1 se pueden observar algunos de los casos mencionados y los diferentes escenarios alcanzados, desde la impugnación directa de un laudo arbitral por medio de una AEP, hasta la impugnación del fallo que rechaza el recurso de casación que tiene como antecedente a su vez la anulación de un laudo.

Existen todavía varias causas pendientes de resolución en la Corte Constitucional -tanto en admisión como en sustanciacióny, si bien la admisión de una AEP dependerá de las circunstancias particulares de cada caso en específico, es perfectamente posible impugnar casi toda resolución, desde un laudo -así como otras

13-EP; Luz Marina Levoyer Masson, Caso No. 1457-13-EP; Ángel Mateo Noblecilla Rosillo, en calidad de Alcalde del cantón Pasaje, Caso No. 0031-14-EP; Eduardo Francisco Diez Cordovez, en calidad de Gerente General y representante legal de la compañia Quasar Náutica Expeditions S.A., Caso No. 0543-14-EP; Alan Narváez, Caso No. 0605-14-EP; Alberto Cárdenas Dávalos, en calidad de representante legal de la compañia Confianza de Seguros y Reaseguros S.A., Caso No. 0831-14-EP; Danilo Morales Jaramillo, en calidad de procurador judicial de Roberto Murillo Cavagnaro, gerente general de la Corporación Financiera Nacional, Caso No. 0920-14-EP; Christel Gaibor Flor, en calidad de Directora Nacional de Asuntos Internacionales y Arbitraje encargada del Procurador General del Estado, Caso No. 0949-14-EP; Jaime Eduardo Castañeda y Miriam Elena Reyes Solano, Caso No. 1281-14-EP; Darwin Stalyn Guzmán Arias y Eduardo Alberto Serpa Ochoa, Caso No. 1818-14-EP; Antonio Martínez Borrero ofreciendo poder ratificación de la Compañía Negocios Automotores Neohyundai S.A., Caso No. 0063-15-EP; Anibal Carrera Arboleda en calidad de gerente general de INMOEUROPA CIA LTDA, Caso No. 0078-15-EP; Leopoldo Enríquez Espinosa, en calidad de gerente general de DILUSERVICIOS EMPRESARIALES S.A., Caso No. 0177-15-EP; Roberto Carmigniani Valencia, en calidad de procurador judicial de PAZCORP S.A., Caso No. 0266-15-EP; Roberto Carmigniani Valencia, en calidad de procurador judicial de PAZCORP S.A., Caso No. 0267-15-EP; Edmund Helmut Negwer y Judith Guadarrana, Caso No. 0408-15-EP; Iván Gustavo Vivanco Morales, Caso No. 0575-15-EP; Hugo Almeida, en calidad de liquidador de MANAGERNERACIÓN S.A., y Carlos González, en calidad de apoderado de LA FABRIL S.A., Caso No. 0802-15-EP; Eduardo Carmigniani Valencia, en calidad de procurador judicial de CONECEL, Caso No. 0932-15-EP.

18. Véase por ejemplo, los casos: Francisco Grijalva Muñoz, en calidad de Director Nacional de Asuntos Internacionales y Arbitraje de la Procuraduría General del Estado, y Marcelo Aguayo, en calidad de Director Nacional de Asesoría Jurídica y Procurador Judicial del ministro de Salud Pública, Caso No. 1703-11-EP; Clemente Bravo Riofrio e Ignacio Arias García, por los derechos que representan del Gobierno Autónomo Descentralizado de Santa Rosa, en calidades de Alcalde y Procurador Síndico Municipal, Caso No. 0976-12-EP; CELTEL CONSTRUCCIONES Y SERVICIOS LTDA, Caso No. 1114-12-EP; Carlos Julio Machado Vallejo, en calidad de gerente general subrogante y representante legal de la Empresa Pública Metropolitana de Desarrollo Urbano de Quito EPMDUQ, Caso No. 133813-EP; Miguel Ángel Valdivieso Valencia, Caso No. 1362-13-EP; Ángel Mateo Noblecilla Rosillo, en calidad de Alcalde del cantón Pasaje, Caso No. 0031-14-EP; Christel Gaibor Flor, en calidad de Directora Nacional de Asuntos Internacionales y Arbitraje encargada del Procurador General del Estado, Caso No. 0949-14-EP; Leopoldo Enríquez Espinosa, en calidad de gerente general de DILUSERVICIOS EMPRESARIALES S.A., CASO No. 0177-15-EP. 
decisiones de un Tribunal arbitral- hasta los diferentes pronunciamientos de las Cortes Provinciales y de la Corte Nacional. En consecuencia, los autos de admisión de la Corte Constitucional son una relevante referencia para determinar el criterio de la Corte, no obstante, sus argumentos más importantes se reflejan en las sentencias emitidas en los últimos años.

\section{Pronunciamientos de la Corte Constitucional}

De los diferentes escenarios antes descritos se pueden observar varios resultados, especialmente respecto a la admisibilidad de una AEP en contra de laudos y resoluciones relacionadas con su nulidad. Adicionalmente, la Corte Constitucional ha emitido importantes fallos que abordan estas circunstancias. A continuación se detallan las sentencias más significativas emitidas por la Corte que recogen los principales argumentos relativos al control constitucional del sistema arbitral. De su análisis se evidenciarán las diferentes posturas mantenidas por la Corte que, debido a su eclecticismo, han dado lugar a más preguntas que respuestas.

\subsection{Sentencia Caso No. 0008-2008-DI ${ }^{19}$}

En este caso la Corte Constitucional trató la constitucionalidad del artículo 59 del Código de Procedimiento Civil ${ }^{20}$, específicamente respecto a la aplicación del trámite ordinario en la acción de nulidad de los laudos arbitrales. La Corte desechó la declaratoria de inconstitucionalidad del artículo señalando que este no es contrario a la Constitución -de 1998 ni a la de 2008- pero sin antes realizar importantes precisiones.

La Corte indicó que la declaratoria de inaplicabilidad general del artículo atentaría a la seguridad jurídica de otras reclamacio-

19. Corte Constitucional para el Período de Transición, RO Sup. No. 605, 4/06/2009, Caso No. 0008-2008DI, sentencia de 5/05/2009.

20. Código de Procedimiento Civil, Art. 59: “Toda controversia judicial, que según la ley, no tiene un procedimiento especial se ventilará en juicio ordinario", RO Sup. No. 687, 18/05/1987. 
nes judiciales que se ventilan en juicio ordinario y que "otra cosa es que la realidad de la administración de justicia en el país no haya podido cristalizar los principios constitucionales de celeridad y eficacia". Adicionalmente, la Corte estableció que las vías alternativas de solución de conflictos "son mecanismos que pretenden evitar que se incurra en los mismos vicios que, lamentablemente, afectan a la administración de justicia", en donde lo que se busca es una solución oportuna y ágil.

De esta forma, la Corte enfatizó que la Ley de Arbitraje y Mediación prevé un procedimiento específico para el trámite de nulidad $^{21}$. Consideró que este es el único trámite a observarse, sin que pueda aplicarse el artículo 59 del Código de Procedimiento Civil, al ser este procedente únicamente en los casos en que la ley no ha determinado un procedimiento especial.

Finalmente, es importante notar que la Corte hace referencia expresa al criterio de la Procuraduría General del Estado, la cual coincidía en la inaplicabilidad del artículo 59 del Código de Procedimiento Civil en materia de arbitraje $\mathrm{e}^{22}$.

\subsection{Sentencia No. 0006-10-SEP-CC ${ }^{23}$}

Esta sentencia marca un importante precedente a favor del arbitraje en el sistema ecuatoriano. Sin perjuicio de haberse alegado como excepción la incompetencia del juez al haber una cláusula arbitral, el proceso continuó hasta llegar a la Corte Suprema de Justicia (hoy Corte Nacional). Se presentó una acción extraordinaria de protección alegando la violación de los derechos de tu-

21. LAM, N. 13, Art. 31.

22. La sentencia textualmente establece: "El Dr. Néstor Arboleda Terán, Director Nacional de Patrocinio, Delegado del Procurador General del Estado, entre otras cosas, indica que coincide con el criterio del Presidente de la ex Corte Superior (hoy Corte Provincial), en el sentido de que en materia de arbitraje, sistema alternativo de justicia, no es aplicable el artículo 59 del Código de Procedimiento Civil. Sin embargo, el Código de Procedimiento Civil contiene las reglas a seguir en todas las controversias judiciales, las que en caso de declararse la inaplicabilidad general del artículo 59, se verían afectadas e impedidas de sustanciación."

23. Corte Constitucional para el Período de Transición, RO Sup. No. 159, 16/03/2010, Caso No. 0712-09EP, sentencia de 24/02/2010. 
tela judicial efectiva y seguridad jurídica, por cuanto las cortes y juez inferiores se atribuyeron y fallaron en el caso, a pesar de no ser competentes.

La Corte Constitucional estableció que se vulneró el derecho del accionante al debido proceso al no haber sido juzgado por el juez o autoridad competente, con observancia del trámite propio de cada procedimiento. En consecuencia, se aceptó la acción extraordinaria de protección por haberse demostrado la violación de los derechos de tutela judicial efectiva y seguridad jurídica, y se dejaron sin efecto los fallos inferiores. La Corte finalmente dispuso que el proceso se retrotraiga a la fase procesal de conclusión de la audiencia de conciliación y contestación de la demanda, a efecto de que el juez de primera instancia resuelva la excepción de incompetencia.

\subsection{Sentencia No. 063-12-SEP-CC ${ }^{24}$}

En este caso una acción de nulidad de laudo llegó a la Corte Nacional y una acción extraordinaria de protección fue interpuesta en contra de la sentencia que negó el recurso de casación presentado. El caso alcanzó la Corte Nacional después de haberse presentado una acción de nulidad de laudo, la apelación de la sentencia que resolvió esta acción y varios recursos horizontales a lo largo del proceso.

La Corte Constitucional precisó que la acción extraordinaria de protección "no constituye una instancia adicional a las previstas en la jurisdicción ordinaria" y que por lo tanto "no compete a la Corte Constitucional pronunciarse acerca del asunto controvertido en el proceso judicial (...), esto es, determinar si existe o no nulidad del laudo $(\ldots)^{\prime 25}$.

24. Corte Constitucional para el Período de Transición, RO Sup. No. 735, 29/06/2012, Caso No. 1443-10EP, sentencia de 27/03/2012.

25. Sentencia N. 063-12-SEP-CC, N. 24, p. 7. 
La Corte hizo además una importante consideración:

[L]a acción de nulidad de laudo arbitral (...) agotó todas las instancias en la jurisdicción ordinaria, pues el fallo de primera instancia fue apelado para ante la Primera Sala de lo Civil de la Corte Provincial de Justicia de Pichincha. Por recurso de casación interpuesto por dicha compañía, el proceso judicial pasó a conocimiento de la Sala de lo Civil, Mercantil y de la Familia de la Corte Nacional de Justicia, la cual expidió la sentencia que es objeto de impugnación, y finalmente se expidió auto de aclaración del fallo de casación ${ }^{26}$.

La Corte declaró que no existió vulneración de derechos constitucionales y rechazó la acción extraordinaria de protección; sin embargo, de la argumentación de la Corte se evidenciaría que se espera que se agoten todas las instancias en la jurisdicción ordinaria para que la acción extraordinaria de protección prospere.

\subsection{Sentencia No. 155-12-SEP-CC ${ }^{27}$}

En este caso se impugnó, mediante una acción extraordinaria de protección, una providencia de un tribunal arbitral que no dio paso a una acción de nulidad de laudo. El accionante atacó la motivación del tribunal, sin embargo, la Corte Constitucional determinó que el tribunal fue claro, racional y actuó fundamentadamente, por lo que negó la acción extraordinaria de protección y declaró que no hubo vulneración de derechos constitucionales.

Si bien la acción extraordinaria de protección fue rechazada, la importancia de esta sentencia radica en la posibilidad de impugnar una providencia de un tribunal arbitral por medio de una acción extraordinaria de protección. Así, por ejemplo, si la Corte hubiera evidenciado que la decisión del tribunal que negó la acción de nulidad no se encontraba motivada, la acción extraordi-

26. Ídem, p. 9.

27. Corte Constitucional para el Período de Transición, RO Sup. No. 743, 11/07/2012. Caso No. 1037-10EP, sentencia de 17/04/2012. 
naria de protección hubiera sido, dejando todo lo demás constante, aceptada.

\subsection{Sentencia No. 169-12-SEP-CC ${ }^{28}$}

Esta sentencia marca expresamente la postura de la Corte Constitucional a favor del control constitucional de laudos arbitrales. Se presentó una acción extraordinaria de protección en contra de un laudo arbitral, del cual a su vez se presentó una acción de nulidad que fue rechazada por la Presidencia de la Corte Provincial.

La Corte Constitucional definió varios aspectos que influirían en casos futuros. Se establecieron las siguientes puntualizaciones:

(i) Los laudos arbitrales tienen la misma fuerza que una sentencia ejecutoriada, en consecuencia, son impugnables por medio de la acción extraordinaria de protección ${ }^{29}$.

(ii) La acción de nulidad debe ser agotada previamente a la interposición de una acción extraordinaria de protección, con la única excepción de que dicha acción se muestre inadecuada o ineficaz para la resolución del problema ${ }^{30}$.

La Corte señaló también que al someterse a arbitraje se limita legítimamente "el ejercicio del derecho a la doble instancia, lo que no implica una renuncia al mismo, sino una declaración previa de conformidad con el resultado obtenido (... $)^{\prime \prime 31}$. Finalmente, considerando que el accionante pretendía que se trate una cuestión de mera legalidad, la Corte concluyó que no existió vulnera-

28. Corte Constitucional para el Periodo de Transición, Caso No. 1568-10-EP, RO Sup. No. 756, 30/07/2012, sentencia de 26/04/2012.

29. Ídem, p. 12.

30. Ídem, p. 13. El artículo 61 numeral 3 de la LOGJCC establece como un requisito para la interposición de la acción extraordinaria de protección la " [...] demostración de haber agotado los recursos ordinarios y extraordinarios, salvo que sean ineficaces o inadecuados o que la falta de interposición de estos recursos no fuera atribuible a la negligencia del titular del derecho constitucional vulnerado".

31. Ídem, p. 14. La Corte continuó indicando que: "La única posibilidad de lograr un pronunciamiento al respecto por medio de la acción extraordinaria de protección sería la demostración de la existencia de una vulneración directa a una norma constitucional, fuera de lo considerado 'materia transigible', y no de manera mediata, como se pretende en la demanda." 
ción de derechos constitucionales y negó la acción extraordinaria de protección.

Si bien la Corte no desarrolló a profundidad la residualidad de la acción extraordinaria de protección en materia arbitral, es razonable concluir que dependiendo de la configuración de una de las causales de la acción de nulidad -en teoría- deberá o no agotarse la acción de nulidad ${ }^{32}$. En consecuencia, podría ser factible la impugnación directa de un laudo por medio de una acción extraordinaria de protección si es que lo que configuró la violación de derechos constitucionales no se encuentran dentro de las causales de la acción de nulidad (e.g. falta de motivación, interés público, etc.).

\subsection{Sentencia No. 081-13-SEP-CC ${ }^{33}$}

Este caso tiene como precedente una acción de nulidad que fue negada por la Presidencia de Corte Provincial del Guayas. Se presentó un recurso de casación y el accionante presentó una acción extraordinaria de protección en contra de la decisión de la Corte Nacional que no admitió el recurso. El accionante atacó la motivación de la Corte Nacional ${ }^{34}$, sin embargo, la Corte Constitucional resolvió que no se vulneraron derechos y rechazó la acción extraordinaria de protección interpuesta.

32. En el presente caso el Presidente de la Corte Provincial rechazó la acción de nulidad porque la falta de motivación, que atacaba el accionante no es una de las causales para interponer la acción de nulidad.

33. Corte Constitucional del Ecuador, RO Sup. No. 154, 3/01/2014, Caso No. 0091-13-EP, sentencia de 23/10/2013.

34. La decisión judicial que se impugna es el auto del 04 de diciembre de 2012, dictado por la Sala de Conjueces lo Civil y Mercantil de la Corte Nacional de Justicia, el cual estableció: “[...] Esta Sala considera que la impugnación de un laudo arbitral no es un asunto de conocimiento, en atención a lo prescrito en el inciso final del Art. 32 de la Ley de Mediación y Arbitraje. El arbitraje es un mecanismo de solución de conflictos de jurisdicción privada por terceras personas, que no tienen la calidad e investidura de los jueces de la jurisdicción común, por no ser designados por el poder público, sustrayéndolos de la jurisdicción común, previo sometimiento voluntario de las partes en tal decisión, cuya existencia impide a la Función Judicial conocer de las cuestiones litigiosas sometidas al arbitraje. Así la disposición del Art. 31 de la Ley de Mediación y Arbitraje estatuye la inapelabilidad del laudo arbitral, por lo que la decisión arbitral se torna irrevocable, y podrá obtenerse su ejecución forzada del mismo modo que las sentencias de última instancia, siguiendo la vía de apremio". 


\section{La Corte sostuvo que:}

[E]n los procesos arbitrales, debido a que al someterse a un proceso de este tipo, las partes están realizando una manifestación de aceptación previa al resultado que se vaya a adoptar, dentro del proceso arbitral y, por consiguiente, de su inapelabilidad por esta causa ${ }^{35}$.

La Corte rechazó la acción extraordinaria de protección advirtiendo que el derecho de recurrir un fallo ${ }^{36}$ del accionante no fue vulnerado, considerando que "este ha podido plantear recurso de nulidad del laudo arbitral impugnado y además plantear recurso extraordinario de casación" ${ }^{\prime 37}$. Así, se evidencia el criterio de la Corte en que la posibilidad de plantear estos recursos determinó la no vulneración de derechos constitucionales, ni la indefensión del accionante ${ }^{38}$.

\subsection{Sentencia No. 123-13-SEP-CC ${ }^{39}$}

Una vez más la decisión sobre una acción de nulidad de laudo fue atacada mediante varios recursos horizontales y verticales. Finalmente, alegando falta de motivación, se interpuso una acción extraordinaria de protección en contra de la sentencia dictada por la Presidente de la Corte Provincial de Justicia del Guayas que declaró la nulidad de un laudo arbitral.

La Corte Constitucional aceptó la AEP, declarando la vulneración del derecho constitucional a la motivación. La Corte Constitucional consideró que la Presidente de la Corte Provincial no expresó ni explicó de manera clara sus argumentos, por lo que

35. Sentencia No. 081-13-SEP-CC, N. 33, p. 9.

36. La Corte Constitucional ha mantenido que el derecho a recurrir no es absoluto. Véase, Caso No. 31 10-CN, Sentencia No. 001-11-SCN-CC; y, Caso No. 0499-11-EP, Sentencia No. 0045-13-SEP-CC.

37. Sentencia No. 081-13-SEP-CC, N. 33, p. 9.

38. Ibídem. La Corte estableció: "En consecuencia, se advierte que el derecho al debido proceso, respecto de la garantía de poder recurrir el fallo, alegado por el legitimado activo, no ha sido vulnerado, pues como se puede evidenciar, este ha podido plantear recuso de nulidad del laudo arbitral impugnado y además plantear recurso extraordinario de casación, los mismos que le resultaron adversos a sus intereses; es decir, en ningún momento se lo ha dejado en indefensión."

39. Corte Constitucional del Ecuador. Caso No. 1542-11-EP, RO Sup. No. 222, 09/04/2014, sentencia de $19 / 12 / 2013$. 
dejó sin efecto sentencia de nulidad de laudo impugnada y dispuso que sea conocida por el presidente subrogante de la Corte Provincial de Justicia del Guayas.

La Corte determinó que "los procesos de solución de conflictos previstos por el sistema arbitral en el contexto del Estado constitucional de derechos y justicia, enfrentan el desafío de constitucionalizarse" ${ }^{40}$, y que "no está efectuando un análisis sobre cómo el tribunal arbitral debió haber valorado aquellos elementos probatorios" sino que lo importante es el acompañamiento de un argumento lógico ${ }^{41}$.

En esta sentencia la Corte confirmó que la sentencia que resuelve una acción de nulidad es constitucionalmente impugnable mediante una acción extraordinaria de protección ${ }^{42}$ y que un laudo arbitral "debe ser impugnable mediante acción extraordinaria de protección cuando durante el proceso arbitral o en el laudo se han vulnerado derechos constitucionales o el debido proceso $^{\prime \prime 4}$.

La Corte reiteró que la acción extraordinaria de protección no es un mecanismo ordinario que pueda ser usado para corregir errores de fondo o de forma ${ }^{44}$, pero indicó que la vulneración de derechos constitucionales puede producirse por el órgano jurisdiccional que efectúa el control del laudo, así como por el tribunal $\operatorname{arbitral}^{45}$.

40. Ídem, pp. 7-8: “(...) aquellos procedimientos tendientes a solucionar conflictos o controversias previstos en la Ley de Arbitraje y Mediación y normas conexas, deben observar y aplicar los principios y garantías constitucionales, sin que aquellos signifique una invasión inadecuada de los aspectos de fondo del asunto sometido al arbitraje y que procura una solución mediante la expedición de un laudo arbitral. Dicho en otras palabras, los procesos de solución de conflictos previstos por el sistema arbitral en el contexto del Estado constitucional de derechos y justicia, enfrentan el desafío de constitucionalizarse, aplicando de manera integral los principio, normas y reglas constitucionales a estos métodos, pero fundamentalmente conservando la esencia y naturaleza del sistema arbitral (...)".

41. Ídem, p. 15.

42. Ídem, p. 8.

43. Ídem, p. 9.

44. Ídem, p. 10. "La Corte Constitucional reitera que la acción extraordinaria de protección no es un mecanismo de impugnación ordinario tendiente a corregir errores en la sustancia (errores in iudicando) o en la forma (errores in procedendo) de la causa o resolución arbitral, pues aquellos deben ajustarse a los mecanismos de impugnación ordinarios previstos en el ordenamiento jurídico y resueltos por la autoridad competente".

45. Ibídem. 
Adicionalmente, la Corte consideró que:

[L]as transgresiones y vulneraciones a derechos constitucionales y al debido proceso podrían producirse en la etapa prearbitral, establecidas para el arbitraje administrado de acuerdo al artículo 2 de la Ley de Arbitraje y Mediación y que se refiere a las competencias de los artículos 10,11, 12, 13, 15, 17, 21 letra a) y letra b) de la LAM otorgan al Director o Directora del Centro de Arbitraje ${ }^{46}$.

Respecto a esta última afirmación, resulta evidente la posición de la Corte Constitucional de que todo sería constitucionalmente controlable, o al menos todo acto o foro donde potencialmente puedan producirse violaciones a derechos constitucionales.

\subsection{Sentencia No. 173-14-SEP-CC ${ }^{47}$}

El caso se originó con el rechazo de una acción de nulidad. La apelación de esta sentencia también fue rechazada, ante lo cual se presentó recurso de casación, el cual fue negado, al igual que el posterior recurso de hecho interpuesto. Agotados todos estos recursos, mediante una acción extraordinaria de protección, se impugna el auto por el cual se niega el recurso de hecho en contra del auto que a su vez niega el recurso de casación ${ }^{48}$.

Interesantemente, en esta sentencia la Corte estableció que:

[L]a acción de nulidad surge como consecuencia de las causales previstas en el artículo 31 respecto del laudo arbitral, lo cual no genera ni da lugar a considerar que la acción de nulidad es una acción independiente del laudo que tiene un trámite adicional

46. Ibídem.

47. Corte Constitucional del Ecuador, Caso No. 1114-12-EP, RO Sup. No. 406, 30/12/2014, sentencia de $15 / 10 / 2014$.

48. La Corte Provincial negó el recurso de hecho considerando que "el recurso de hecho procederá cuando se haya negado el trámite del recurso de casación únicamente en los procesos de conocimiento y por cuanto el presente proceso no es de aquellos que pone fin a un proceso, se niega el recurso de hecho (...)". 
al previsto en el artículo mencionado, ya que por el contrario surge de este, conforme lo determinado en la ley.

Siendo así, la restricción impuesta en el artículo 30 -inapelabilidad laudo arbitral-genera un efecto directo también en la acción de nulidad, ya que caso contrario la Ley hubiera establecido la facultad de recurrencia de la sentencia que resuelva dicha acción. (Énfasis añadido)

Continuando con su argumentación, la Corte hace referencia a la sentencia N. ${ }^{\circ}$ 081-13-SEP-CC ${ }^{49}$, determina que "existen disposiciones expresas que conforme lo manifestado impiden la presentación de recursos adicionales a la acción de nulidad respecto de laudos arbitrales" ${ }^{50}$ y que "los jueces se sujetaron a lo dispuesto tanto en la normativa constitucional como legal que regula esta clase de procedimiento por lo que no existe vulneración del derecho constitucional $(\ldots)^{\prime \prime 51}$.

La Corte aprovecha para reiterar que el derecho a recurrir no es absoluto ${ }^{52}$ y que el que la ley no prevea la posibilidad de presentar recursos no implica una vulneración al derecho a la tutela judicial efectiva, "sino por el contrario, implica el acceso a la justicia bajo un marco de certeza jurídica" 53 .

Finalmente la Corte determina que el negar el recurso de hecho, amparándose en el artículo 31 de la Ley de Arbitraje y Mediación, los jueces "no establecieron una restricción que no se en-

49. Ídem, p. 11. La Corte estableció: "Este criterio fue sostenido por la Corte Constitucional en la sentencia No. 081-13-SEP-CC, en la que al analizar un auto dictado por la Sala de Conjueces de lo Civil y Mercantil de la Corte Nacional de Justicia que inadmitía a trámite un recurso de casación propuesto en contra de una acción de nulidad, al considerar a esta como un recurso incidente, esta Corte señaló: Una de las características principales del proceso arbitral, es la establecida en el artículo 30 de la Ley de Arbitraje y Mediación, el cual señala que los laudos arbitrales son inapelables; por lo que, las partes, al aceptar someterse a un proceso arbitral, aceptan someterse a la decisión de estos adoptada”.

50. Ibídem. La Corte también señaló que “(...) existe una disposición constitucional que establece que estos procedimientos se efectuarán con sujeción a la ley, y en efecto existe una ley que regula expresamente los recursos que caben respecto de un laudo arbitral."

51. Ibídem.

52. Véase, sentencia No. 173-14-SEP-CC, N. 47, pp. 12-13. Véase Corte Constitucional del Ecuador. Sentencia No. 008-13-SCN-CC, de 14/03/2013, RO Sup. No. 915, 19/03/2013: "Sin embargo, aun cuando el derecho a un doble pronunciamiento es un derecho constitucional, esto no significa que el legislador deba establecer recursos en todo proceso (...)".

53. Véase, sentencia No. 173-14-SEP-CC, N. 47, p. 13. 
cuentre determinada por la normativa jurídica, ya que conforme lo dicho, la misma Ley expresamente es la que restringe la posibilidad de recurrir dentro de los procesos de arbitraje y mediación"54 y declara que no existe vulneración de derechos constitucionales y niega, por lo tanto, la acción extraordinaria de protección planteada.

\subsection{Sentencia No. 113-15-SEP-CC ${ }^{55}$}

Este caso tiene como precedente un primer laudo arbitral que fue anulado porque uno de los árbitros no se encontraba en el país a la fecha en la que se expidió. El segundo laudo fue impugnado directamente mediante acción extraordinaria de protección, solicitando previa y únicamente la aclaración del laudo, la cual fue rechazada.

La Corte aplicó la sentencia No. 123-SEP-CC, que determinó que un laudo arbitral es impugnable mediante acción extraordinaria de protección, e indicó que "se vulneró el derecho al debido proceso respecto de la garantía de ser juzgado por juez o autoridad competente y con observancia del trámite propio de cada procedimiento" 156 .

En su fallo, la Corte Constitucional declaró la vulneración del derecho al debido proceso y el derecho a la seguridad jurídica ${ }^{57}$, aceptó la acción extraordinaria de protección y dejó sin efecto el segundo laudo expedido. Ordenó finalmente retrotraer el procedimiento arbitral hasta la audiencia de sustanciación de la demanda, "mediante la cual se declaró competente sin determinar el alcance de su competencia en relación a las cláusulas arbitrales invocadas ni el trámite propio del procedimiento $(\ldots)^{\prime \prime 58}$.

\footnotetext{
54. Ídem, p. 14.

55. Corte Constitucional del Ecuador, RO Sup. No. 510, 28/05/2015, Caso No. 0543-14-EP, sentencia de 08/04/2015.

56. Ídem, p. 21. Véase, CRE, N. 1, Art. 76, numeral 3.

57. Véase, CRE, N. 1, Arts. 76 y 82.

58. Véase, sentencia No. 113-15-SEP-CC, N. 55, pp. 25-26.
} 
Este caso evidencia nuevamente la posibilidad de impugnar un laudo arbitral directamente mediante una acción extraordinaria de protección $\mathrm{y}$, al mismo tiempo, cómo un proceso arbitral puede incurrir en irregularidades que derivan en una prolongación preocupante en la resolución de controversias ${ }^{59}$.

\subsection{Sentencia No. 124-15-SEP-CC ${ }^{60}$}

La Corte Constitucional trató dos casos acumulados relacionados con el rechazo de recursos de casación interpuestos por un Ministerio y la Procuraduría General del Estado, derivados a su vez de la negativa de la acción de nulidad de laudo, sentencia que a su vez fue apelada y cuyo fallo confirmó la sentencia de la Presidencia de la Corte Provincial.

Se rechazaron los recursos considerando que la sentencia objeto del recurso de casación no proviene de un juicio de conocimiento y porque los laudos arbitrales no son susceptibles de ningún otro recurso que no establezca la Ley de Arbitraje y Mediación. Ante esta posición se alegó que al rechazar los recursos de casación y de hecho se vulneró el derecho al debido proceso y, en particular, el derecho a la defensa y el derecho a ser oído ${ }^{61}$.

La Corte Constitucional aclaró que no todo tipo de restricción a instancias o etapas procesales superiores constituye necesariamente una afectación al derecho al debido proceso y que la vulneración se produce cuando:

59. El primer laudo fue expedido el 13 de marzo de 2009; el segundo laudo, el 20 de enero de 2014; y, la sentencia de la Corte que resolvió retrotraer todo lo actuado hasta la audiencia de sustanciación de la demanda, es de fecha 8 de abril de 2015.

60. Corte Constitucional del Ecuador, RO Sup. No. 516, 05/06/2015, Casos No. 1279-11-EP y 1280-11EP acumulados, sentencia de 22/04/2015.

61. Ídem, p. 6. Se indica que la Procuraduría General del Estado señaló que tanto la Corte Nacional de Justicia como la exCorte Suprema de Justicia han aceptado a trámite recursos de casación tales como los procesos: 546-10 (Municipio de Quito en contra de la Compañía Constructora GAR S.C.C.); 29207 (Senatel en contra de Otecel S. A., y Conecel S. A.); 57-07 (Transinvest S. A., Seguranza Cía. Ltda., y Metromedical Cía. Ltda., en contra de GMI Financial Group INC.); 106-2007 (Pacifictel contra Nedertel). 
[E]xistiendo la posibilidad de acceder a una etapa o instancia superior a través de un recurso previsto en el ordenamiento jurídico, la autoridad judicial impide conceder a alguna de las partes procesales dicha impugnación por decisiones injustificadas o irrazonables ${ }^{62}$.

La Corte realiza la distinción entre la imposibilidad de formular recurso de apelación en contra de laudos arbitrales y la acción de nulidad de laudo ${ }^{63}$. Acordemente, diferencia "la posibilidad de presentar un recurso de casación en contra de la sentencia que fue dictada en segunda instancia [...], al resolver la acción de nulidad planteada" ${ }^{\prime 64}$. Así, considera la Corte, que se "han denegado injustificadamente los recursos de casación solicitados [...], más aún cuando las partes intentaron activar el recurso de hecho o recurso de queja para que tal petitorio sea atendido $[\ldots]^{\prime \prime 65}$ y calificó a esta negativa como irrazonable e injustificada ${ }^{66}$.

Finalmente, la Corte declaró la vulneración de derechos constitucionales, dejó sin efecto los autos impugnados, y dispuso que las causas sean remitidas a la Corte Nacional de Justicia "a fin de que el tribunal de casación resuelva lo que en derecho corresponda" 67 .

\subsection{Sentencia No. 270-15-SEP-CC ${ }^{68}$}

Esta sentencia refleja un interesante escenario que podría contrarrestar el potencial uso abusivo de la acción extraordinaria de protección en materia arbitral. Una entidad pública y la Procuraduría General del Estado impugnaron, mediante acción extraordinaria de protección, un auto dictado por un tribunal

62. Ídem, p. 15.

63. Ídem, p. 16.

64. Ídem, p. 17.

65. Ídem, p. 18.

66. Ídem, p. 19.

67. Ibídem.

68. Corte Constitucional del Ecuador, RO Sup. No. 607, 14/10/2015, Caso No. 1945-11-EP, sentencia de $19 / 08 / 2015$. 
arbitral que resolvió negar la solicitud de revocatoria de la providencia en la cual dispuso que, en virtud de la acción de nulidad de laudo interpuesta, se realice el pago de una importante caución ${ }^{69}$.

El Tribunal advirtió que, de no hacerlo, se remitiría el proceso a la Corte Provincial de Justicia sin orden de suspensión de laudo arbitral, ante lo cual se interpuso la acción extraordinaria de protección. Se solicitó a la Corte Constitucional que se declare la vulneración de derechos fundamentales $\mathrm{y}$, adicionalmente, la falta de competencia del Tribunal Arbitral, por no existir el pronunciamiento favorable previo de la Procuraduría General del Estado.

De esta manera, la Corte entró a revisar la decisión del tribunal arbitral y concluyó que el auto superó satisfactoriamente el test de motivación, toda vez que este es razonable, lógico y comprensible ${ }^{70}$. Además, concluyó no se debía contar con el pronunciamiento favorable del Procurador General del Estado porque a la fecha de suscripción del contrato (2005) se observó la normativa constitucional vigente, que no lo requería ${ }^{71}$. En consecuencia, la Corte Constitucional declaró que no existió vulneración de derechos constitucionales y negó la acción extraordinaria de protección.

\section{EClecticismo en la Corte}

De las sentencias señaladas, es evidente que en un inicio la Corte Constitucional adoptó una postura más favorable hacia el arbitraje. Se estableció que el procedimiento de anulación de un

69. El tribunal arbitral, de conformidad con el artículo 31 de la Ley de Arbitraje y Mediación, fijó la caución en \$244.771,80 USD para suspender los efectos del laudo arbitral. Se indica que el tribunal estimó los posibles daños derivados de la demora en la ejecución del laudo arbitral, tomando en cuenta la tasa de interés legal establecida por el Banco Central del Ecuador, sobre un período de 36 meses, porque así comprendería el estimado para resolver la acción de nulidad más 18 meses adicionales en caso de interponerse otros recursos.

70. Véase sentencia No. 124-15-SEP-CC, N. 61, pp. 15-17.

71. Ídem, p. 19. 
laudo no es el ordinario -con lo cual coincidía la Procuraduría General del Estado- que los medios alternativos de solución de controversias no deben incurrir en los mismos "vicios que, lamentablemente, afectan a la administración de justicia"72 y además se defendieron los principios in dubio pro arbitri y Kompetenz-Kompetenz $z^{73}$.

Más tarde, debido al uso de la acción extraordinaria de protección como medio de impugnación, la Corte Constitucional señaló que esta no constituye una instancia adicional; sin embargo, determinó que debe respetarse su naturaleza extraordinaria y residual. ${ }^{74}$ A pesar de esta precisión, todavía no estaba del todo claro qué acciones o recursos debían agotarse para que prospere una AEP y se abrió la posibilidad de impugnar laudos arbitrales directamente, cuando aquello que se impugnaba resultaba de una violación constitucional que no era objeto de una acción de nulidad (e.g. motivación) ${ }^{75}$.

Luego, la Corte Constitucional indicaría expresamente que los laudos arbitrales son impugnables por medio de la acción extraordinaria de protección y que la acción de nulidad debía ser agotada, salvo que esta no fuera adecuada o eficaz ${ }^{76}$. Esta postura, aunque criticada, dio más claridad al criterio que tendría la Corte al admitir o no una AEP. No se aclaró la duda relativa al agotamiento de recursos como la apelación y casación, pero la posibilidad de acceder a estos recursos incidiría en la aceptación o rechazo de una $\mathrm{AEP}^{77}$, aunque también se dejó clara la posibilidad de impugnar un laudo directamente ${ }^{78}$.

La Corte reafirmaría posteriormente su postura de que el sistema arbitral enfrenta "el desafío de constitucionalizarse"79, pero

72. Véase, sentencia Caso No. 0008-2008-DI, N. 19.

73. Véase, sentencia No. 0006-10-SEP-CC, N. 23.

74. Véase, sentencia No. 063-12-SEP-CC, N. 24.

75. Véase, sentencia No. 155-12-SEP-CC, N. 27.

76. Véase, sentencia No. 169-12-SEP-CC, N. 28.

77. Véase, sentencia No. 081-13-SEP-CC, N. 33.

78. Véase, sentencia No. 113-15-SEP-CC, N. 55.

79. Véase, sentencia No. 123-13-SEP-CC, N. 39. 
seguidamente al parecer cambiaría de criterio al establecer que la inapelabilidad de un laudo arbitral "genera un efecto directo también en la acción de nulidad, ya que caso contrario la Ley hubiera establecido la facultad de recurrencia de la sentencia que resuelva dicha acción" $" 80$.

Resulta extremadamente interesante este breve cambio de postura, especialmente porque basándose en el mismo argumento de que el derecho a recurrir no es absoluto, entre otros, se llegan a conclusiones opuestas. Por un lado, la Sentencia No. 173-14-SEP-CC argumenta que la negativa de un recurso de hecho -que buscaba la casación de una sentencia que rechazó la apelación de una acción de nulidad- no vulneró derechos. Adicionalmente, no es menos interesante señalar que quien interpuso la AEP en este caso fue un particular, en contra de una entidad pública a la que favoreció un laudo arbitral. Esta decisión seguiría la línea argumental del caso No. 0008-2008-DI, aunque al parecer ha sido olvidado por la Corte.

Por otro lado, y con menos de un año de diferencia, la Corte Constitucional, distinguiendo la imposibilidad de formular recurso de apelación en contra de laudos arbitrales y la acción de nulidad de laudo, sostuvo que se produciría una vulneración de derechos cuando, existiendo la posibilidad de "acceder a una etapa o instancia superior a través de un recurso previsto en el ordenamiento jurídico", se impide injustificadamente este acceso. En el caso en mención se consideró que hubo tal vulneración al haber denegado injustificadamente los recursos de casación solicitados por un Ministerio y la Procuraduría General del Estado ${ }^{81}$.

Finalmente, la Corte consideró que no hubo violación de derechos constitucionales en la fijación de una importante caución con motivo de la interposición de una acción de nulidad. ${ }^{82}$ Esta decisión representa una solución muy oportuna y un incentivo muy fuerte frente al potencial abuso de la acción de nulidad de

80. Véase, sentencia No. 173-14-SEP-CC, N. 47.
81. Véase, sentencia No. 124-15-SEP-CC, N. 61.
82. Véase, sentencia No. 270-15-SEP-CC, N. 69. 
laudo y de otros potenciales recursos en contra de las sentencias o decisiones relacionadas con su nulidad. Si la decisión de un tribunal se encuentra debidamente motivada, la exigencia de una caución -sin la cual se remitiría la causa a la Corte Provincial sin orden de suspensión del laudo- obligaría a las partes a analizar detenidamente los méritos de su caso. Adicionalmente, la LAM solo prevé la suspensión de la ejecución de un laudo rindiendo caución para quien interpone la acción de nulidad, lo cual no incluiría la interposición de una acción extraordinaria de protección. Sin embargo, la Ley Orgánica de Garantías Jurisdiccionales y Control Constitucional establece expresamente que la admisión de la acción extraordinaria de protección "no suspende los efectos del auto o sentencia objeto de la acción" $"$.

\section{Conclusión}

De los casos expuestos se evidencia un tratamiento diferenciado a la acción extraordinaria de protección en el sistema arbitral ecuatoriano. Si bien ahora es claro que es posible impugnar directamente un laudo e incluso otras providencias de un tribunal arbitral, todavía no se resuelve el antiguo debate sobre la admisibilidad y procedencia de recursos ordinarios o extraordinarios en contra de las sentencias que resuelven la nulidad de un laudo. Es pertinente la diferenciación y puntualizaciones en el ámbito legal (e.g. que la inapelabilidad prevista por la LAM es del laudo y no de la sentencia que resuelve su nulidad, etc.) y constitucional (e.g. que no se deben agotar todos los recursos ordinarios y extraordinarios para que sea admisible una $\mathrm{AEP}$, a menos que sean ineficaces o inadecuados). No obstante, uno de los principales problemas que deben atacar las cortes es la incertidumbre y la inseguridad jurídica, lo cual ha repercutido directamente en la admisibilidad y posterior aceptación o rechazo de acciones extraordinarias de protección y en la administración de justicia en general. 
La misma Corte Constitucional -en el olvidado caso No. 0008-2008-DI- advirtió que los métodos alternativos de solución de controversias "son mecanismos que pretenden evitar que se incurra en los mismos vicios que, lamentablemente, afectan a la administración de justicia" ${ }^{84}$, lo que se concreta con el establecimiento de procedimientos extremadamente largos y sentencias inconsistentes, incompatibles con la búsqueda de soluciones oportunas y ágiles ${ }^{85}$. Las reglas deben ser claras y no es posible que se las aplique con beneficio de inventario dependiendo de quién intervenga. De igual forma, el arbitraje no se encuentra excluido de la aplicación de la Constitución y los tribunales arbitrales y cortes que resuelvan acciones de nulidad deberán respetarla en las mismas condiciones y bajo los mismos parámetros. El principal reto entonces es determinar si la acción extraordinaria de protección efectivamente aporta a la eficaz administración de justicia en el sistema arbitral.

Es posible que en un arbitraje puedan haber violaciones de carácter constitucional, pero deben haber procedimientos más eficientes, con reglas claras y condiciones suficientes que permitan que no se pierdan los beneficios del arbitraje. De lo contrario, la Corte Constitucional, en lugar de tratar casos que en verdad ameritan un control constitucional, terminará inundada de acciones extraordinarias de protección que no buscan sino impugnar decisiones meramente comerciales disfrazadas de constitucionales. Similarmente, la falta de celeridad, consistencia y armonía entre y dentro de las cortes perjudica a todo el sistema de administración de justicia, lo cual no solo afecta a este ámbito, sino a todo el país en general.

84. Véase, sentencia Caso No. 0008-2008-DI, N. 19.

85. Ibídem. 
TABLA 1: Tratamiento de las acciones extraordinarias de protección

\begin{tabular}{|c|c|c|c|c|c|c|c|c|c|c|c|c|c|c|c|c|}
\hline \multirow[t]{2}{*}{ CORTE } & & \multicolumn{15}{|c|}{ CASO } \\
\hline & & 1 & 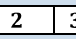 & 3 & 4 & $\mathbf{5}$ & 6 & 7 & $\mathbf{8}$ & 9 & 10 & 11 & 12 & 13 & 14 & 15 \\
\hline \multirow{3}{*}{$\begin{array}{c}\text { CORTE } \\
\text { CONSTI- } \\
\text { TUCIO- } \\
\text { NAL } \\
\end{array}$} & \multicolumn{16}{|c|}{ Acción extraordinaria de protección } \\
\hline & $\begin{array}{l}\mathbf{D} \\
\mathbf{F}\end{array}$ & $\mathbf{R}$ & $\mathbf{R}$ & $\mathbf{R}$ & $\mathbf{A}$ & $\mathbf{A}$ & $\mathbf{R}$ & $\mathbf{P}$ & $\mathbf{R}$ & & $\mathbf{P}$ & $\mathbf{P}$ & $\mathbf{P}$ & & & $\mathbf{P}$ \\
\hline & $\begin{array}{l}\text { D } \\
\text { A }\end{array}$ & $\checkmark$ & \begin{tabular}{l|l} 
& $\cdot$ \\
\end{tabular} & $\checkmark$ & $\checkmark$ & $\sqrt{ }$ & $\checkmark$ & $\checkmark$ & $\checkmark$ & $x$ & $\checkmark$ & $\checkmark$ & $\checkmark$ & $x$ & $x$ & $\checkmark$ \\
\hline \multirow[b]{3}{*}{$\begin{array}{c}\text { CORTE } \\
\text { NACIO- } \\
\text { NAL }\end{array}$} & \multicolumn{16}{|c|}{ Casación } \\
\hline & $\begin{array}{l}\text { D } \\
\text { F }\end{array}$ & & $\mathbf{R}$ & & & & & $\mathbf{R}$ & & & $\mathbf{R}$ & & & & & \\
\hline & $\begin{array}{l}\text { D } \\
\text { A }\end{array}$ & & $\sqrt{ }$ & & $\begin{array}{l}\text { CP: } \\
\times \\
0 \\
0 \\
x\end{array}$ & & $\begin{array}{l}\text { CP: } \\
\dot{x} \\
\bullet \bullet \\
x\end{array}$ & $\begin{array}{l}\text { CP: } \\
X \\
\cdots \\
\text { CN: } \\
\checkmark\end{array}$ & $\begin{array}{l}\text { CN: } \\
x\end{array}$ & $\begin{array}{l}\text { CP: } \\
X \\
\bullet \bullet \\
N C: \\
X \\
\odot \\
\end{array}$ & \begin{tabular}{l}
$\mathrm{CP}:$ \\
$X$ \\
\hdashline. \\
$\mathrm{NC}:$ \\
$r$ \\
\end{tabular} & & $\begin{array}{l}\text { CP: } \\
X \\
\odot \\
\end{array}$ & & & \\
\hline \multirow{8}{*}{$\begin{array}{c}\text { CORTE } \\
\text { PROVIN- } \\
\text { CIAL }\end{array}$} & \multicolumn{16}{|c|}{ Apelación } \\
\hline & $\begin{array}{l}\text { D } \\
\text { F }\end{array}$ & & $\mathbf{R}$ & & $\mathbf{R}$ & & $\begin{array}{l}\mathbf{R} \\
\odot\end{array}$ & & & & & & $\mathbf{R}$ & & & \\
\hline & $\begin{array}{l}\text { D } \\
\text { A }\end{array}$ & & $\checkmark$ & & $\sqrt{ }$ & X & $\checkmark$ & & & $x$ & & $\begin{array}{l} \\
\\
\text { NC: } \\
X\end{array}$ & $\checkmark$ & & & \\
\hline & \multicolumn{16}{|c|}{ Acción de nulidad } \\
\hline & $\begin{array}{l}\mathbf{D} \\
\mathbf{F}\end{array}$ & & $\mathbf{R}$ & $\mathbf{R}$ & $\begin{array}{l}\mathbf{R} \\
\odot\end{array}$ & A & $\mathbf{R}$ & $\mathbf{R}$ & $\mathbf{R}$ & $\mathbf{R}$ & $\mathbf{R}$ & $\mathbf{R}$ & $\mathbf{R}$ & & A & \\
\hline & $\begin{array}{l}\text { D } \\
\text { A }\end{array}$ & $x$ & $\checkmark$ & $\checkmark \mid$ & $\checkmark$ & $\checkmark$ & $\checkmark$ & $\sqrt{ }$ & $\sqrt{ }$ & $\checkmark$ & $\checkmark$ & $\checkmark$ & $\checkmark$ & & $\checkmark$ & \\
\hline & & & & & & & & & & & & & & 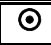 & & \\
\hline & \multicolumn{16}{|c|}{ Laudo arbitral } \\
\hline \multicolumn{17}{|c|}{ * Información actualizada hasta diciembre de 2015.} \\
\hline$\odot$ & \multicolumn{16}{|c|}{ Aclaración y ampliación solicitada y negada. } \\
\hline$\bullet$ & \multirow{2}{*}{\multicolumn{16}{|c|}{$\begin{array}{l}\text { Recurso de hecho en contra de negativa de casación. } \\
\text { Recurso de hecho en contra de negativa de apelación. }\end{array}$}} \\
\hline$\cdot$ & & & & & & & & & & & & & & & & \\
\hline$\sqrt{ }$ & \multicolumn{3}{|c|}{ Admitida } & \multicolumn{3}{|c|}{ CP } & \multicolumn{3}{|c|}{$\begin{array}{l}\text { Corte } \\
\text { Provincial }\end{array}$} & \multicolumn{4}{|c|}{$\mathbf{A}$} & \multicolumn{3}{|c|}{ Aceptada } \\
\hline$x$ & \multicolumn{3}{|c|}{ No admitida } & \multicolumn{3}{|c|}{$\mathbf{C N}$} & \multicolumn{3}{|c|}{$\begin{array}{l}\text { Corte } \\
\text { Nacional }\end{array}$} & \multicolumn{4}{|c|}{$\mathbf{R}$} & \multicolumn{3}{|c|}{ Rechazada } \\
\hline DF & \multicolumn{3}{|c|}{$\begin{array}{l}\text { Decisión } \\
\text { sobre el fondo }\end{array}$} & \multicolumn{3}{|c|}{ DA } & \multicolumn{3}{|c|}{$\begin{array}{l}\text { Decisión } \\
\text { admisión }\end{array}$} & $\mathbf{P}$ & $\mathbf{P}$ & & & & ecisió & \\
\hline Caso & No. & & & & aso & & & Jo. & & & Caso & & & No & & \\
\hline 1 & 103 & 7-10 & & 7 & & & & $441-12$ & -EP & & 13 & & & & $00-1$ & 3 -EP \\
\hline 2 & 144 & 3-10 & & 8 & & & & $091-13$ & -EP & & 14 & & & & 53-1 & 3-EP \\
\hline 3 & 156 & $8-10$ & EP & 9 & & & & $501-13$ & -EP & & 15 & & & & $38-1$ & 3-EP \\
\hline 4 & $\begin{array}{l}127 \\
\mathrm{EP}\end{array}$ & $9 / 12$ & 30-11- & \begin{tabular}{l|l}
-10 & 10
\end{tabular} & & & & $518-13$ & -EP & & - & י-י-ים & & & 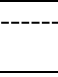 & \\
\hline 5 & 154 & $2-11$ & & 11 & & & & $879-13$ & -EP & & יו-יניר & ----- & & & ני-ני- & ----ים \\
\hline 6 & 111 & 4-12 & & 12 & & & & $880-13$ & & & - & ---- & & & 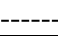 & ---- \\
\hline
\end{tabular}

